\title{
PRAISEWORTHINESS AND ENDOGENOUS GROWTH
}

\author{
David M. Levy, Dalibor Roháč*
}

\begin{abstract}
:
This paper demonstrates that increasing returns to scale can be sustained when agents care about praiseworthiness of their conduct. Unlike the desire to attain approbation from external sources, the notion of praiseworthiness seems to have been neglected by contemporary economic literature. Yet the relevance of praiseworthiness as an internal motivational force was stressed by a number of classical economists. We construct an endogenous growth model in which agents derive utility not only from their consumption but also from praiseworthiness of their action. In such a setting, the motivation by praiseworthiness is able to generate positive and accelerating growth of output per labourer in steady state. The main implication of our model is that the existence of increasing returns depends critically on presence of sufficient approbation attributed to creativity. Furthermore, the presence or the absence of these rewards may be susceptible to explain the cross-sectional differences in growth rates, growth miracles and growth disasters.
\end{abstract}

Keywords: research and development, approbation, praiseworthiness, endogenous growth

JEL Classification: B12, O31, O41, N00

\section{Introduction}

Endogenous growth theory asserts that without appropriate incentives for research and development (R\&D), new ideas and technological innovations will be underprovided relative to what would be the socially efficient outcome. Economists usually recommend that there ought to be government support for basic scientific research, ${ }^{1}$ protection of intellectual property ${ }^{2}$ and that socially wasteful occupations - such as theft, tax collection or rent-seeking - be not sufficiently attractive to motivate an outflow of talented individuals from the R\&D sector. ${ }^{3}$

It is thus claimed that without a proper way of rewarding creators of non-excludable ideas, economies will not be able to turn on the engine of increasing returns.

In this paper, we provide a preference-based explanation for why there might exist individual motives for provision of non-excludable knowledge even when some or all

* David M. Levy, Center for Study of Public Choice, Carow Hall, MSN 1D3, George Mason University, Fairfax, VA 22030 (davidmlevy@gmail.com). Dalibor Roháč, St Antony’s College, Woodstock Road, Oxford, OX2 6JF (dalibor.rohac@economics.ox.ac.uk). We have benefitted from helpful comments from Steven N. Durlauf and one anonymous referee.

1 Phelps (1966).

2 Aghion and Howitt (1992).

3 Murphy, Shleifer and Vishny (1991). 
of these incentives are absent. When individuals care about approbation and when production of new ideas is rewarded by approbation, then new ideas will be produced, even though they bring no pecuniary rewards to their creators. More specifically, we will assume that individuals care about praiseworthiness of their action. Praiseworthiness is an internal form of reward, which stems from the moral, cultural and religious characteristics of the society. In our model, agents consider it praiseworthy to participate in production and diffusion of new knowledge. The fact that not all world societies and world cultures share this view may help us understand the cross sectional differences in rates of economic growth. Likewise, we argue that changes in this reward structure, which happen over time may help us to understand sudden growth miracles and growth disasters.

For some time, economists have been interested in economic effects of culture. Mokyr (2005) provides a discussion of the interplay of science, culture and economic progress in 18th and 19th century England and he identifies the general pro-scientific attitude as one of the key factors triggering the Industrial Revolution. Landes (1998) identifies intellectual and cultural openness as one of the key determinants of economic prosperity in the long run. Barro and McCleary (2003) study the relationship between religiosity and economic growth. Their main finding is that belief in heaven and hell increases growth rates, while church attendance is suceptible to decrease them. Their results, however, do not offer deeper insights into the relationship between particular religious beliefs, human conduct and specific economic outcomes. In our view, it is plausible that this relationship depends on approbation which is attributed to various activities by religion and culture.

The easiest way to understand approbation is to consider rewards received by individuals to be not scalars but vectors. Besides pecuniary rewards in terms of wages, profits and rents, individuals engaging in various activities may receive also nonmaterial forms of remuneration. There may be occupations which carry a lesser degree of pecuniary remuneration but which remunerate one with fame or approbation. In this paper, the degree of approbation that an individual action receives depends on the degree to which the individual works for the ,common good.“ In this specific setting, the notion of ,common good" reduces to the production of non-excludable ideas. Once the mechanism of rewarding individuals by approbation is in place, it is straightforward to observe that in the endogenous growth setting such mode of rewarding is susceptible of generating increasing returns.

The setting in which we are embedding increasing is a standard endogenous growth model. Obviously, increasing returns are not a feature unique to endogenous growth models ${ }^{4}$ and vice versa, endogenous growth models can - given a particular choice of parameter values - fail to generate increasing returns. Yet endogenous growth theory has been by far the most popular way of formalizing increasing returns and that, in our view, justifies us in using it as the vehicle to carry our results. One could also argue that increasing returns can well take place without the motivational assumptions which we are using in this paper. That is an entirely correct claim. Our ambition has not been to downplay alternative explanations of increasing returns but rather to show one particular way how culture and approbation can shape economic outcomes.

In the following section we offer a discussion of the notion of praiseworthiness in the works of classical economists. We will see that, in spite of its apparent obscurity,

4 Buchanan and Yoon (1999). 
praiseworthiness has been long recognised as an important motivating force of individual action. In Section 3, we present a model of endogenous growth in which agents are motivated by their desire to attain praiseworthiness. Section 4 offers an agenda for empirical investigation of this hypothesis. Section 5 concludes.

\section{Economics, Approbation and Praiseworthiness}

Are economists entitled to assume that individuals care about approbation? After all, the general consensus of the profession is that preference-based explanations ought to be performed with utmost caution, since they risk turning the whole concept of utilitymaximisation into a tautology. ${ }^{5}$

But approbation has the curious property of being a matter of preference and observable in cultural norms. In particular, through mere exercise of introspection, economists ought to be quick to realise that approbation does represent a goal for many, if not all, of them. ${ }^{6}$

Paul Samuelson once famously stated:

In the long run, the economic scholar works for the only coin worth having - our own applause (Samuelson 1962, p. 18).

Two decades later, he subscribed to the same view:

Scientists are as avaricious and competitive as Smithian businessmen. The coin they seek is not apples, nuts, and yachts; nor is it coin itself, or power as that term is ordinarily used. Scholars seek fame. The fame they seek...is fame with their peers - the other scientists whom they respect and whose respect they strive for (Samuelson, 1986).

That fame is a driving force of scientific enquiry in general as is acknowledged in current literature on philosophy of science. ${ }^{7}$

Brennan and Pettit (2000) and Cowen and Glazer (2007) analyse economic consequences of esteem-seeking behaviour. The former focus on broader implications of esteem with regard to overcoming of various market failures and sustaining exchange, the latter discuss the role of esteem in explaining individual behaviour on labour markets. Frey (1997) pioneered the analysis of non-pecuniary motivational forces (work morale) in a principal-agent framework. Bénabou and Tirole (2002, 2003) provide an elegant treatment of self-esteem as a motivating force of workers. Cowen and Sutter (1997) extend the treatment of esteem to political markets and analyse the effects of fame-seeking behaviour on the outcomes of political processes.

The notion of approbation includes internal motivations, such as the desire to attain praiseworthiness by morally laudable conduct or the desire to satisfy one's self-esteem. It includes also external motivations, such as the desire to be famous and receive public approbation. With the notable exception of Frey and Bénabou and Tirole, all of the above mentioned studies work with external sources of motivation.

For classical economists, however, praiseworthiness seems to play at least as important role as praise in providing incentives for action. ${ }^{8}$

5 See Stigler and Becker (1977) for a critique of preference-based explanations in which preferences have no anchor in observable phenomena.

6 See also Hansen and Weisbrod (1972).

7 See Zamora Bonilla (2002).

8 Peart and Levy $(2005,2007 a)$. 
In Theory of Moral Sentiments, Adam Smith speaks thusly about praiseworthiness:

Man naturally desires, not only to be loved, but to be lovely; or to be that thing which is the natural and proper object of love. He naturally dreads, not only to be hated, but to be hateful; or to be that thing which is the natural and proper object of hatred. He desires, not only praise, but praiseworthiness; or to be that thing which, though it should be praised by nobody, is, however, the natural and proper object of praise. He dreads, not only blame, but blame-worthiness; or to be that thing which, though it should be blamed by nobody, is, however, the natural and proper object of blame (Smith 1759, III.I.8).

Unlike praise, praiseworthiness is an internal motivation. It is clear that the concept of praise and praiseworthiness are closely connected:

The love of praise-worthiness is by no means derived altogether from the love of praise. Those two principles, though they resemble one another, though they are connected, and often blended with one another, are yet, in many respects, distinct and independent of one another (Ibid., III.I.9).

Their [other people‘s] praise necessarily strengthens our own sense of our own praiseworthiness. In this case, so far is the love of praise-worthiness from being derived altogether from that of praise; that the love of praise seems, at least in a great measure, to be derived from that of praiseworthiness (Ibid., III.I.10).

Still, Smith warns that these two should not be confused, for their origin is different:

The most sincere praise can give little pleasure when it cannot be considered as some sort of proof of praise-worthiness. It is by no means sufficient that, from ignorance or mistake, esteem and admiration should, in some way or other, be bestowed upon us. If we are conscious that we do not deserve to be so favourably thought of, and that if the truth were known, we should be regarded with very different sentiments, our satisfaction is far from being complete. The man who applauds us either for actions which we did not perform, or for motives which had no sort of influence upon our conduct, applauds not us, but another person. We can derive no sort of satisfaction from his praises (Ibid., III.I.11).

Obviously, Smith was not the only one to focus his attention on praiseworthiness as an internal motivational factor. Several other classical economists of great stature, to say the least, discussed at length the issue of praiseworthiness. ${ }^{9}$ James Mill states:

The same considerations account for that remarkable phenomenon of our nature, eloquently described, but not explained, by Adam Smith, that, in minds happily trained, the love of Praiseworthiness, is a stronger feeling, than the love of actual Praise, the Dread of actual Blame. It is one of those cases, in which, by the power of association, the secondary feeling becomes more powerful than the primary (Mill 1829, II, p. 298).

In his comment on this passage, John Stuart Mill emphasises:

This paragraph, unexplained, might give the idea that the author regarded praiseworthiness and blameworthiness as having the meaning not of deserving praise or blame, but merely of being likely to obtain it. But what he meant is, that the idea of deserving praise is but a more complex form of the association between our own or another person's acts or character, and the idea of praise. To deserve praise, is, in the great majority of the cases which occur in life, the principal mode of obtaining it; though the praise is seldom accurately proportioned to the desert. And the same may be said of blame. A powerful association is thus, if circumstances are favourable, generated between deserving praise and obtaining it; and hence between deserving praise, and

$9 \quad$ See Peart and Levy (2007a) and Peart and Levy (2007b). 
all the pleasurable influences on our lives, of other people's good opinion. And this association may become sufficiently strong to overcome the direct motive of obtaining praise, where it is to be obtained by other means than the desert; the rather, as the desire of undeserved praise greatly counteracted by the thought that people would not bestow the praise if they knew all. That what has now been stated was really the author's meaning, is proved by his going on to say, that praiseworthiness and blameworthiness, as motives to action, have reference , not to what is, or to what shall be, but what ought to be, the sentiments of mankind." (Mill 1869, pp. 298-299).

Customary as motivation by praiseworthiness was in classical political economy, it has practically disappeared from modern economic science. Obviously, one of the purposes of the present work is to return the notion of praiseworthiness to the centre of interest of economists, for - as we believe - it is susceptible to shed new light on great many issues, including the most fundamental problems of economic growth.

As we will see, the central question of the relationship between praiseworthiness and economic outcomes lies in the distinction between actions that are praiseworthy and those that are not. Following Levy (1999), a case can be made that - for Smith engaging in high-stake gambles is praiseworthy in its own right. Similarly to the Stoic tradition, it is the willingness to commit to action with low probability of success, which is an object of moral approbation. Obviously, winning such a gamble will attract praise from external sources. But even in the case when one does not win the gamble in question, he can still enjoy approbation from the impartial spectator. It is his heroic conduct as such that makes him an object of praiseworthiness, not the actual success of his action.

\section{Approbation and Endogenous Growth}

\subsection{Scientists, Praise and Praiseworthiness}

This analytical perspective appears to be especially well suited to analyse amateur science, i.e. R\&D in the absence of intellectual property rights. Without intellectual property, new ideas are non-excludable. As a result, the inventor will not be able to secure any monetary income from his invention. However, by being first to discover a certain idea, the scientist will attract public praise and esteem. And even in cases when he does not succeed in the gamble and sacrifices resources to invent something that has already been known, his conduct will be equally praiseworthy, even though he will receive little or no amount of fame and public recognition. Merton (1973) provides a compelling case for acknowledging that many of the rewards which scientists receive are of non-monetary nature and include fame - often in the form of having one's name associated with a theorem, law or paradox.

Approbation gives us thus two motivating factors which may lead economic agents to sacrifice their time and resources to $R \& D$. The first one is the desire for praise and fame coming from other agents. The second one is the praiseworthiness of one's action and the approbation which one receives from the impartial spectator. At the first sight, we may be tempted to collapse these two into one common motivating factor which will simply lead one to engage in $\mathrm{R} \& \mathrm{D}$ and receive approbation from internal and external sources. However, erasing the distinction between praise and praiseworthiness would not be warranted as it entails the conceptual distinction between internal and 
external motivational forces. And it entails also some important technical differences in the way how these are introduced into economic models.

Levy (1988) presents a model of praise-seeking behaviour. In his setting, individuals maximise a utility function of the form

$$
\mathrm{U}=\mathrm{U}(\mathrm{c}(\mathrm{u}, \mathrm{t}), \mathrm{f}(\mathrm{t}))
$$

where $f$ is the quantity of fame - or approbation - commanded by the individual, $c$ is his overall consumption and $\mathrm{u}$ is the amount of time spent in pursuing market activities. Obviously,

$$
\mathrm{c}(\mathrm{u}, \mathrm{t})=\mathrm{w}(\mathrm{t}) \mathrm{u}(\mathrm{t})
$$

when we disregard any effects of one's fame on his wage. Furthermore, he assumes that

$$
f(t)=g(1-u(t))
$$

where $g($.$) is an increasing function. This is to say that the change in fame bestowed$ upon the agent is an increasing function of the amount of time spent working in the production of new ideas. Thus, at any moment the work in R\&D will add to the stock of approbation. Previous accomplishments and research will build up a stock of approbation which the agent is able to consume. Isaac Newton, Albert Einstein or Adam Smith do not have to spend any time doing research to remain famous. Their contributions have secured them fame and praise for very extended, if not unlimited, periods of time. In other words, fame is a stock and not a flow.

When one thinks about praiseworthiness - which we denote a in the remainder of this paper - things become drastically different. Unlike fame, praiseworthiness cannot be accumulated. To be praiseworthy, it is not sufficient to have done something worthwhile in the past. At any moment, to command praiseworthiness one has to perform certain activities - such as spending time and resources in the R\&D sector. Thus praiseworthiness will be generated according to the following schedule:

$$
\mathrm{a}(\mathrm{t})=\gamma(1-\mathrm{u}(\mathrm{t}))
$$

$\gamma>0$. In what follows, we assume that individuals care about their consumption and their praiseworthiness, without considering the actual external praise that they receive.

Obviously, alternative models could be constructed, in which individuals would derive utility from external sources of approbation. One could formulate an optimal control problem using the assumptions from Levy (1988). Also a stochastic programming approach could be used to model R\&D as a gamble in which the winner receives both approbation from the impartial spectator and a dose of fame from the part of the general public, whereas the other contestants enjoy solely the internal form of approbation. In this setting, the desire for fame would be driving force for the creative activity of inventors and praiseworthiness would be the motivating factor for the absorbers of knowledge. Fame would thus drive innovation while culturally determined approbation would facilitate its diffusion. In all of these cases, the technical apparatus needed to conduct analysis within such environments would be highly 
complicated and it is questionable whether we would be able to arrive at tractable solutions. In this paper, we have therefore chosen to work with the weakest of all possible assumptions - specifically, we assume that agents care only about the praiseworthiness of their actions and receive no amount of external approbation even if they succeed in their endeavours. This simple framework alone allows us to generate the main result - that quest for approbation is susceptible to generate the additional motive for engaging in R\&D and that praiseworthiness alone is able to generate increasing returns. What is more, this analytical framework enables to link economic performance with the unit reward in terms of praiseworthiness $\gamma$. This allows us to look for links between a society's economic growth and activities which are considered worthy of praise.

\subsection{Model}

We construct a growth model with exogenous savings rate, exogenous labour-leisure substitution and with endogenous technological change. At any moment, individuals derive utility from their consumption and from the approbation that their action receives. Without a preference for approbation, the economy converges to a steady state in which there is no growth per capita as there are no incentives for research producing non-excludable knowledge. With a preference for approbation, positive and accelerating growth of output and consumption per labourer follows.

Let us have an economy with endogenous technological change, populated by identical infinitely lived individuals. The production function is

$$
\mathrm{Y}(\mathrm{t})=(\mathrm{K}(\mathrm{t}))^{\alpha}[\mathrm{A}(\mathrm{t}) \mathrm{u}(\mathrm{t}) \mathrm{L}(\mathrm{t})]^{1-\alpha}
$$

where $K$ is the total stock of capital, $L$ is number of labourers, $A$ is the level of technology and $u$ is the fraction of time spent working in the goods-producing sector. We further assume

$$
\begin{aligned}
& \dot{\mathrm{L}}=\mathrm{nL} \\
& \dot{\mathrm{K}}=\mathrm{sY}-\delta \mathrm{K} \\
& \dot{\mathrm{A}}=((1-\mathrm{u}) \mathrm{L})^{\theta} \mathrm{A},
\end{aligned}
$$

$0<\theta<1$, where $\mathrm{n}$ is the exogenous level of population growth, $\mathrm{s}$ is the level of savings, $\delta$ is the rate of depreciation of the capital stock and $1-u$ is the fraction of time spent working in the ideas-producing sector. The fact that $\theta<1$ reflects decreasing returns from labour in production of new ideas. There is no leisure. It is straightforward to observe that

$$
\dot{\mathrm{Y}}=\mathrm{F}_{\mathrm{K}} \dot{\mathrm{K}}+\mathrm{F}_{\mathrm{L}} \dot{\mathrm{L}}+\mathrm{F}_{\mathrm{A}} \dot{\mathrm{A}}
$$

This implies that

$$
g_{\mathrm{Y}}=\frac{\dot{Y}}{Y} \mathrm{~s} \cdot \mathrm{F}_{\mathrm{K}}-\alpha \delta+(1-\alpha) n+(1-\alpha)((1-\mathrm{u}) \mathrm{L})^{\theta}
$$


The output per labourer and the growth rate per labourer are given by

$$
\begin{aligned}
& \mathrm{y}=\mathrm{k}^{\alpha}[\mathrm{Au}]^{1-\alpha}, \\
& \mathrm{g}_{\mathrm{y}}=\mathrm{s}_{\mathrm{K}} \alpha \delta+(1-\alpha)((1-\mathrm{u}) \mathrm{L})^{\theta}
\end{aligned}
$$

On perfectly competitive markets, wages and real interest rate will be equal to marginal products of labour and capital, exhausting thus the total product:

$$
\begin{aligned}
& \mathrm{w}=(1-\alpha) \mathrm{K}^{\alpha}[\mathrm{AuL}]^{-\alpha} \mathrm{Au} \\
& \mathrm{r}=\alpha \mathrm{K}^{\alpha-1}[\mathrm{AuL}]^{1-\alpha} \\
& Y=w L+r K .
\end{aligned}
$$

This means that there is no pecuniary reward for engaging in R\&D. It is straightforward to note that without nonpecuniary motivation for $\mathrm{R} \& \mathrm{D}$, the growth rate of output per labourer will be

$$
\mathrm{g}_{\mathrm{y}}=\mathrm{sfK}-\alpha \delta,
$$

converging to 0 in the steady state.

We assume that individuals care not only about their consumption, c, but also about the approbation that their action receives. By approbation we mean here the praiseworthiness that their action commands at each moment. No amount of approbation is related to the work within the goods-producing sector. Work in the $\mathrm{R} \& \mathrm{D}$ sector, however, is remunerated by $\gamma$ units of approbation. The individual seeks to maximise

$$
\int_{0}^{\infty} e^{-\rho t} \mathrm{U}(\mathrm{c}(\mathrm{u}, \mathrm{t}), \mathrm{a}(\mathrm{t})) \mathrm{dt}
$$

subject to

$$
\begin{gathered}
c(u, t)=(1-s) w(t) u(t) \\
a(t)=\gamma(1-u(t)),
\end{gathered}
$$$$
\text { and }
$$

$\gamma>0$. The Euler equation for this problem is

$$
\mathrm{U}_{\mathrm{c}}(1-\mathrm{s}) \mathrm{w}+\mathrm{Ua}(-\gamma)=0 .
$$

For a CES utility function of the form

$$
\mathrm{U}(\mathrm{c}, \mathrm{a})=\left(\beta \mathrm{a}^{\delta}+(1-\beta) \mathrm{c}^{\delta}\right)^{\frac{1}{\delta}},
$$

$0<\delta<1$, we obtain the following first-order condition:

$$
(1-\beta)((1-s) w)^{\delta} u^{\delta-1}=\beta \gamma^{\delta}(1-u)^{\delta-1} .
$$

Solving for u yields

$$
u=\frac{1}{1+\left(\frac{1-\beta}{\beta}\right)^{\frac{1}{\delta-1}}\left(\frac{1-s w}{\gamma}\right)^{\frac{\delta}{\delta-1}}} .
$$


This implies that along the steady state, the growth rate per labourer will be

$$
g_{y}=(1-\alpha)\left(\left(\frac{1}{1+\left(\frac{1-\beta}{\beta}\right)^{\frac{1}{\delta-1}}}\right) L\right)^{\theta} \text {. }
$$

Corollary 1 When agents seek approbation, there will be positive and accelerating growth of output per labourer.

Corollary 2 Growth rate of output per labourer is increasing in total population L.

Corollary 3 Growth rate of output per labourer increases when the share of labour on total product 1- $\alpha$ increases.

Corollary 4 Growth rate of output per labourer increases when the preference for approbation $\beta$ increases.

Corollary 5 Growth rate of output per labourer increases when unit reward in terms of praiseworthiness $\gamma$ increases.

Corollary 6 Growth rate of output per labourer increases when the savings rate $s$ increases.

Corollary 1 gives us the central result of the paper. With approbation-seeking agents, increasing returns can be sustained even when production of new ideas brings no monetary rewards. A particular way of looking at this result is that, if knowledge of the model makes is common to all agents, individuals may derive satisfaction from pushing the outcome towards the efficient state of affairs. It is not necessary that they are aware of their doing so, it is sufficient that they behave as if they were doing it with this end in mind. Individual striving for praiseworthiness may be a part of an evolutionarily emerged moral structure that rewards creativity with praiseworthiness. Obviously, the prediction of positive growth rates of output per labourer is consistent with the first of the stylised facts about economic growth, as listed by Kaldor (1963) who asserts that per capita output grows over time and that the growth rate does not tend to diminish.

Corollary 2 follows from our assumptions regarding the production of new ideas. Inventions are made by people and the more numerous human population is, the more rapid technological change will be. In the words of Hayek (1988), ,we have become civilized by the increase of our numbers just as civilization made that increase possible: we can be few and savage, or many and civilized." This result resonates well with Kremer's (1993) findings according to which growth rates increase in total population. To be sure, this holds more as a global tendency than as a factor explaining cross-sectional differences between economic growth in various countries. It is a direct consequence of the fact that knowledge is non-excludable and can be appropriated neither by private individuals nor by a group of individuals living in a clearly delimited territory.

Corollary 3 is a direct result of the conventional assumption that technological change is labour-augmenting, rather than capital-augmenting. The larger the share 
of labour on total product is, the more the growth rate of the economy will react to changes in the stock of knowledge.

Corollaries 4 and 5 summarise the preference origin of the strive for praiseworthiness. On the one hand, the amount of time spent in the R\&D sector depends on $\beta$, one of the parameters of the utility function. The greater the relative importance of praiseworthiness for the utility of the individual, the more time he will spend producing knowledge. In a sense, $\beta$ can be considered as an ultimate given and as identical across individuals. On the other hand, it is the parameter $\gamma$ - the unit reward in terms of praiseworthiness - which appears to be of importance when trying to understand differences in growth rates either in cross-sections of cultures or in time series. This is because praiseworthiness - albeit an internal motivation - depends critically on what one considers praiseworthy. From our perspective, the notion of praiseworthiness is a concept which appears to be shaped at the cultural level.

Corollary 6 may remind one of the traditional neoclassical growth model in which changes in savings rate trigger transitional dynamics that could account for differences in growth rates. Two remarks ought to be done here, however. First, in the Solow-Swan framework, ${ }^{10}$ differences in the savings rate could not explain different growth rates in the steady state. Here, differences in the savings rate account directly for differences in growth rates even when the capital stock per labourer is not changing. Second, in our setting the changes in savings rate affect growth rate not through changes in the steady state level of capital stock but through modifications of relative rewards for the work in the goods-producing sector and in the ideas-producing sector. An increase in savings rate translates as a decrease in consumption at the given moment, increasing thus the relative reward in terms of praiseworthiness for the work in the knowledgeproducing sector.

\section{An Empirical Agenda: Is R\&D Praiseworthy?}

The central assumption of our model is that work in the R\&D sector commands praiseworthiness. The validity of this assumption is culturally dependent. It is not clear that every society, every religion and every civilisation has always rewarded creativity with praiseworthiness. If this had been the case, then human history would have probably been a continual story of discovery and growth of the stock of knowledge. Still, our model predicts that, once creation of knowledge is rewarded by praiseworthiness, increasing returns and growth of output per labourer are possible in the steady state. In addition, the larger the reward in terms of praiseworthiness is, the more will be discovered and faster the growth will be. Our model directs attention towards the sources of praiseworthiness as being the sources of economic growth and suggests that both growth miracles and growth disasters which have occurred over human history could be in part explained by differences in the structure of internal rewards which motivate individuals. There is no question about the fact that the notion of praiseworthiness is a cultural, a moral and a religious issue. As a result, it appears that the possibility of sustained economic growth is critically dependent on presence of sufficient internal rewards for creative action, generated by cultural, moral and

10 See Solow (1956). 
religious institutions. This also represents the key to empirical operationalisation of the model: when it is considered praiseworthy to produce and acquire knowledge, then high rates of economic growth should follow. In contrast, if acquisition of new knowledge and its diffusion are considered indifferent or even blameworthy, then our model predicts stagnation and economic backwardness. If one can find a good proxy for approbation attributed to cultural and intellectual openness, learning and research, this hypothesis will be amenable to formal empirical test. A perfect proxy for this variable is probably unavailable.

The second problem is related to the possibility of reverse causation. A cursory exploratory data analysis using World Values Survey shows that there is strong positive correlation between intellectual openness and growth as well as between measures of tolerance and growth. ${ }^{11}$ However, it might be that these cultural features are just a by-product of economic development. Hence any attempt to subject our hypothesis to formal econometric test would require instrumenting for measures of what is considered praiseworthy - as in Tabellini (2008).

Besides econometric testing, historical evidence can provide indirect means to verify our theory. Since late Middle Ages, some areas of Western Europe - particularly Northern Italy, England and the Netherlands - have entered on a path of unprecedented economic growth, with other European countries eventually catching up. Ultimately, this development has lead to a historically unique level of wealth and prosperity which is now being enjoyed by billions of individuals on the European continent, in the Americas and in Western offshoots around the globe. It is clear that the institutional mix of legal stability, protection of property rights and limited constitutional government played a crucial role. Yet these institutional factors do not exclude presence of other, most notably cultural and religious, elements which might have contributed to this development. In his controversial work, Max Weber (1934) gave credit to the role played by the protestant moral view of world, which was conducive to productive and thrifty behaviour, as well as to adoption and diffusion of knowledge. It is not the purpose of the present paper to evaluate the merits and demerits of Weber's thesis ${ }^{12}$ but we should emphasise that it strikes us as obvious that without an individualistic moral order in which the efforts for the betterment of mankind are rewarded by approbation and praiseworthiness, many of the entrepreneurial and intellectual achievements of the Western world would not be possible. What is more, Mokyr (2005) provides a fascinating narrative of how the cultural atmoshpere fostered innovation and how scientific achievements and progress were considered laudable in the 18th and 19th century England. Especially, as systematic knowledge of physics, biology and chemistry was becoming increasingly non-proprietary, those who were adding to this stock of knowledge wanted to be rewarded by peer recognition and fame, rather than by monetary rewards. According to Mokyr, the general public likewise displayed an important degree of curiosity in scientific advances of the era - which explains the fact that the scholarly journals from this period were usually written in a style accessible to laymen.

The example of the Islamic world is also amenable to an analysis that would take into account internal remuneration for creative action. From the 9 th to the 13 th

11 Precise results and datasets for replication are available on request.

12 See Subrick (2007) for a defense of Weber on empirical grounds. 
centuries, Arab civilisation was without any doubt the most creative and dynamic in the world. This has ceased to be the case from the 14th century on. Never again would the Arab world regain its place as a centre of scholarship, science and economic development. So far, economic historians have not had much to say about the deeper reasons for this fallback. Our model suggests that these causes might relate to the ways how the Islam and the Islamic culture modified the manner how creativity and critical scientific reflection were rewarded. Besides North's (1993) brief description of the decline of Islamic scholarship, Lewis (2002) addresses persuasively the issue of knowledge acquisition in the Islamic world. The prevailing mood during the decline was that ,knowledge was something to be acquired, stored, if necessary bought, rather than grown or developed" (Lewis 2002, p. 39). Also, the idea that Muslims ought to study under the direction of infidel teachers was not conceivable. The predominant view in the Islamic world was that all things worthy of discovery had been discovered by Islamic scholars. Ideas and knowledge of the infidels were not valuable and no or even negative moral rewards were attached to studying and understanding them. In the terms of our model, these views reinforced the existing intellectual and scientific isolation of the Islamic world and contributed to the decay of its economic performance.

Late medieval Japan followed a similar path. In 1630s, the policy of national seclusion - sakoku - was introduced, marking the begining of the Edo period. Sakoku meant that no foreigners and no Japanese could either leave or enter Japan under the penalty of death. Exceptions were granted to Chinese and Dutch merchants. Although Japan did not isolate itself completely from Western science and technology, closedness with regard to the outside world was considered virtuous. It is curious that some historians describe the era between the 1630s edicts and the arrival of Commodore Perry in 1868 partly as an era of economic growth and prosperity. ${ }^{13}$ Measured in 1990 dollars, the Japanese GDP per capita increased from 520 in 1600 to 737 in $1870 .{ }^{14} \mathrm{~A}$ back-of-the envelope calculation shows that this amounts to a yearly growth rate of less than 0.16 per cent.

Finally, the failure of sub-Saharan Africa to generate economic growth might not be completely independent of the way how creativity is rewarded by approbation. To be sure, many competing hypotheses attempt to explain the African growth disaster in myriads of different ways. To us, some explanation of the institutionalist variety appears to be plausible. ${ }^{15}$ Still, the institutional structure is not utterly independent of the moral and cultural order which sanctions bad behaviour by blameworthiness and good behaviour by praiseworthiness. A promising avenue for further research is thus to analyse the channels through which creation of new knowledge is being rewarded - or is not being rewarded - in African cultures.

In a nutshell, the value of the unit reward in terms of praiseworthiness, $\gamma$, is surely not a constant. It may vary both in time and across cultures. It may even happen in certain societies that the work in $R \& D$ ceases to command praiseworthiness. Indeed, it may be the case that in certain cultures conduct which is not compatible with economic development will be rewarded by praiseworthiness. An extreme example of this is the

13 See, e.g., Cullen (2003).

14 Maddison's tables.

15 See Acemoglu, Johnson and Robinson (2001) for a prime example of such explanation. 
behaviour of suicide bombers. They do not seem to enjoy much of the praise of their friends and relatives and appear to act in exchange either for postmortal rewards or for praiseworthiness. In our eyes, understanding the structure through which cultures distribute approbation, blameworthiness and praiseworthiness constitutes the key not only for understanding some of the puzzling issues in economic development but also of the apparently irrational extreme behaviour of some of our contemporaries.

\section{Conclusion}

The aim of this paper was twofold. First, we wished to highlight the notion of praiseworthiness, which was commonly used and understood by classical economists but which seems now - for no obvious reason - to have fallen out of fashion. In our view, returning praiseworthiness to the agenda of modern economists and analysing its economic implications is a worthwhile goal in its own right. Second, we attempted to illustrate the potential importance of praiseworthiness by applying it to perhaps the most interesting and important problem of economic science - to the question whether markets can sustain increasing returns in the long run. Our finding is that, if creativity is rewarded by praiseworthiness and if agents are motivated by praiseworthiness, they will engage in production of non-excludable knowledge, fueling thus the motor of long run growth of output per labourer. This provides an additional explanation complementary with the standard stories as well as with the less orthodox ones ${ }^{16}-$ of the phenomenon of increasing returns to scale.

The way how praiseworthiness is introduced into classical political economy and the way how it is introduced into our model may suggest that it is a purely exogenous and fixed variable. While it indeed appears to be exogenous to other determinants of economic growth, figuring in our model, it does not seem to a fixed and culturally universal constant. As a matter of fact, we believe that differences in ways of how creativity is rewarded by praiseworthiness can help us understand some of the critical differences between the rapidly growing and the stagnating parts of the world. They could also shed light on some of the puzzling growth miracles and growth disasters which have occurred during human history.

From our perspective, future research investigating the economic effects of praiseworthiness should go in two directions. First, it should attempt to find good proxies and instruments for cultural and intellectual openness and to test our hypothesis formally. Second, it ought to analyse the precise ways in which different cultures and different world religions attribute moral approbation to creativity, scientific curiosity, quest for truth and critical reflection. For our model predicts that when these are richly rewarded by praiseworthiness, individuals will tend to engage in knowledge-producing behaviour and when existing cultural, moral and religious order fails to reward them, then the society in question risks being trapped in stagnation and poverty.

\section{References}

16 See Levy and Makowsky (2007). 
Acemoglu, D., S. Johnson and J. A. Robinson (2001), „The Colonial Origins of Comparative Development: An Empirical Investigation," American Economic Review 91, pp. 1369-1401.

Aghion, P. and P. Howitt (1992), „A Model of Growth Through Creative Destruction,“ Econometrica 60 , pp. 323-351.

Barro, R. J. and R. M. McCleary (2003), „Religion and Economic Growth Across Countries," American Sociological Review 68, pp. 760-781.

Benabou, R. J. and J. Tirole (2002), „Self-confidence and Personal Motivation,“ Quarterly Journal of Economics 117, pp. 871-915.

Benabou, R. J. and J. Tirole (2003), „Intrinsic and Extrinsic Motivation," Review of Economic Studies 70, pp. 489-520.

Brennan, G. and P. Pettit (2000), „The Hidden Economy of Esteem," Economics and Philosophy 16, pp. 77-98.

Buchanan, J.M. and Yong J. Yoon (1999), "Generalized Increasing Returns, Euler's Theorem and Competitive Equilibrium." History of Political Economy 31, pp. 511- 523.

Cowen, T. and A. Glazer (2007), „Esteem and Ignorance," Journal of Economic Behavior and Organization 63, pp. 373-383.

Cowen, T. and D. Sutter (1997), „Politics and the Pursuit of Fame," Public Choice 93, pp. 19-35.

Cullen, L. M. (2003), A History of Japan: Internal and External Worlds. Cambridge: Cambridge University Press.

Frey, B. S. (1997), "On the Relationship between Intrinsic and Extrinsic Work Motivation." International Journal of Industrial Organization 4, pp. 427-439.

Hansen, W. L. and B. Weisbrod (1972), „Toward a General Theory of Awards, or, Do Economists Need a Hall of Fame?" Journal of Political Economy 80, pp. 422-431.

Hayek, F. A. von (1988), The Fatal Conceit: The Errors of Socialism. Chicago: University of Chicago Press.

Kaldor, N. (1963), „Capital Accumulation and Economic Growth.“ In F. A. Lutz, D. C. Hague (eds.) Proceedings of a Conference Held by the International Economics Association. London: Macmillan.

Kremer, M. (1993), „Population Growth and Technological Change: One Million B.C. to 1990.“ Quarterly Journal of Economics 108, pp. 681-716.

Landes, D. S. (1998), The Wealth and Poverty of Nations: Why Are Some So Rich and Others So Poor? New York: W.W. Norton.

Levy, D. M. (1999), „Adam Smith's Katallactic Model of Gambling: Approbation from the Spectator." Journal of the History of Economic Thought 21, pp. 81-90.

Levy, D. M. (1988), „The Market for Fame and Fortune." History of Political Economy 20, pp. 615-625.

Levy, D. M., Makowsky, M. D. (2007), "Innovation, Price Dispersion, and Emergent Increasing Returns to Scale." Forthcoming in Journal of Economic Behavior and Organization.

Lewis, B. (2002), What Went Wrong? The Clash Between Islam and Modernity in the Middle East. Oxford: Oxford University Press.

Maddison, A. (2007), Historical Statistics for the World Economy: 1-2003 AD. Available at

http://www.ggdc.net/maddison/Historical_Statistics/horizontal-file_03-2007.xls

Merton, R. K. (1973), Sociology of Science. Edited by N. W. Storer. Chicago: University of Chicago Press.

Mill, J. [1829](1869), Analysis of the Phenomena of the Human Mind. Edited by J. S. Mill. London: Longmans, Green, Reader and Dyer.

Mill, J. S. (1869), „Notes,“ In J. Mill [1829](1869). Analysis of the Phenomena of the Human Mind. Edited by J. S. Mill. London: Longmans, Green, Reader and Dyer.

Mokyr, J. (2005), „Long-Term Economic Growth and the History of Technology.“ In: P. Aghion and S. Durlauf (eds). Handbook of Economic Growth. Elsevier.

Murphy, K. M., A. Shleifer, Vishny, R. W. (1991), „The Allocation of Talent: Implications for Growth." Quarterly Journal of Economics 106, pp. 503-530.

North, D. C. (1993), "The Paradox of the West," EconWPA Paper.

Peart, S. J., Levy, D. M. (2005), The „Vanity of the Philosopher": From Equality to Hierarchy in PostClassical Economics. Ann Arbor: University of Michigan Press. 
Peart, S. J., Levy, D. M. (2007a), "Adam Smith on Leadership, Equity, and the „Distinction of Ranks“.” Paper presented at 2007 Meeting of International Leadership Association

Peart S. J., Levy, D. M. (2007b), "Sympathy in 19th Century Political Economy." Paper Presented at 2007 History of Economics Society Meeting.

Phelps, E. S. (1966), „Models of Technical Progress and the Golden Rule of Research." Review of Economic Studies 33, pp. 133-146.

Samuelson, P. A. (1962), „Economists and the History of Ideas." American Economic Review 52 pp. 1-18.

Samuelson, P. A. (1986), „On the Prowl in an Enchanted Forest.“ New York Times, 12 October 1986.

Smith, A. [1759](1790), The Theory of Moral Sentiments. Sixth Edition. London: A. Millar. http://www. econlib.org/Library/Smith/smMS.html.

Solow, R. M. (1956), „A Contribution to the Theory of Economic Growth." Quarterly Journal of Economics 70, pp. 65-94.

Stigler, G. J., Becker, G. S. (1977), „De Gustibus Non Est Disputandum.“ American Economic Review 67, pp. 76-90.

Subrick, J. (2007), "Religion and Economic Development: Evidence from the Early Twentieth Century." Paper Presented at ASREC Meeting, Tampa, 1-4 November 2007.

Tabellini, G. (2008), "Culture and Institutions." Presidential Address to the EEA, Journal of European Economic Association 6, pp. 255-294.

Weber, M. (1934),. Die protestantische Ethik und der Geist des Kapitalismus. Tübingen: J.C.B. Mohr.

World Values Survey, various years, available at http://www.worldvaluessurvey.org/.

Zamora Bonilla, J. P. (2002), „Scientific Inference and the Pursuit of Fame: A Contractarian Approach.“ Philosophy of Science 69, pp. 300-323. 